\title{
Grandparents Raising Grandchildren: Building Strong Families ${ }^{1}$
}

\author{
Millie Ferrer-Chancy, Larry F. Forthun, and Angela Falcone ${ }^{2}$
}

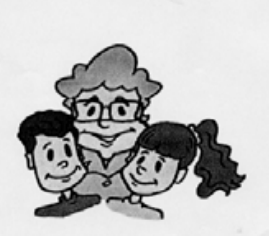

Goal: To provide grandparents with knowledge and skills to develop positive family relationships.

Strong families are defined as having positive beliefs and values, appropriate rules and boundaries, the ability to adapt, and good communication. This is true for any type of family, including grandparents who are parenting their grandchildren.

\section{Beliefs and Values}

Sharing similar values unites and strengthens the family. Although values may differ among families, strong families are similar in that they share time together, have a commitment to each other, and take a positive outlook, even in challenging situations.

\section{Time together}

When you make time together a priority, you show that you appreciate your grandchildren. Family time can be as simple as reading to your grandchildren or

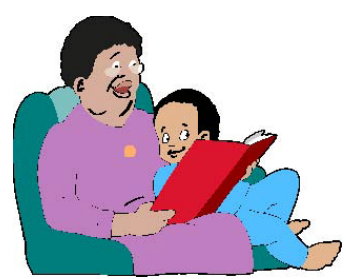
playing with them outside. Creating family traditions such as making Sunday-morning breakfasts together, or taking evening walks, or celebrating holidays and birthdays, are all ways of spending time together. Other activities you can enjoy together are sharing hobbies, participating in outdoor activities, and playing board games. Taking part in activities together creates lasting memories and strengthens bonds between family members.

\section{Commitment}

Family members who are committed to one another are able to keep promises and support one another through rough times. Commitment takes time and effort to build. You can't expect it to blossom overnight. However, by sticking with a difficult family situation even when it seems hopeless, you can begin to develop this family value.

\section{Positive outlook}

There's no doubt that during tough times it is sometimes difficult to be optimistic. As the family leader you can help your family find something positive in every situation and build a stronger family in the process.

One way of building a positive outlook is through remaining hopeful and focusing on the positive strengths of each family member. For example, you can share with your grandchildren all the things they did well that day. Another way of building a positive outlook is to avoid a way of thinking that expects that your grandchildren ought to, should, or must behave a certain way. When you accept your grandchildren for who they are and where they are developmentally, rather than who you think they should be, you are able to avoid negative thinking that leads to a negative outlook. If you can be a good example of positive thinking, your family is more likely to develop a positive outlook, too.

\section{Healthy Limits}

Healthy limits need to be established when sharing feelings, setting expectations, and giving choices to your grandchildren. Healthy limits may include rules that reflect your beliefs and values as well as boundaries that help you distinguish your needs from the needs of your grandchildren.

1. This document is FCS2191, one of a series of the Department of Family, Youth and Community Sciences, Florida Cooperative Extension Service, Institute of Food and Agricultural Sciences (IFAS), University of Florida. First published: March 2002. Revised: August 2009. Please visit the EDIS Web site at http://edis.ifas.ufl.edu.

2. Millie Ferrer-Chancy, Ph.D., interim dean, Florida Cooperative Extension Service, University of Florida; Larry F. Forthun, Ph.D., assistant professor, Department of Family, Youth and Community Sciences; Angela Falcone, former FYCS graduate student; Institute of Food and Agricultural Sciences, University of Florida, Gainesville, FL 32611 
Sharing feelings

How do you know if what you want to share with your grandchildren is appropriate? You must consider how it will affect your grandchildren. If you were to tell your grandchildren the details of your experience, would they become confused, burdened, or overwhelmed? If so, it's probably not a good idea to share these details. Remember, sharing feelings is important. However, be selective and careful about sharing adult details so as not to create an unhealthy boundary.

\section{Setting expectations}

How do you know if the expectations you have for your grandchildren are appropriate? The best way to know is to better understand the stages of child development (see publication, a Crash Course in Child Development). For example, it would be inappropriate to let your granddaughter, age 7 , decide when to go to bed. At 7 years old, your granddaughter does not have the ability to understand the consequences of going to bed late. On the other hand, negotiating a bed time with your 14-year-old grandson would be more appropriate because he can understand the consequences of going to bed late and likely needs to feel he has a say in making some decisions. Having realistic expectations for your grandchildren's behavior will help you establish household rules that are both consistent and flexible.

\section{Giving choices}

How do you know when to give choices to your grandchild? First, it is important to consider your grandchildren's safety: Will they still be safe if they are free to make a particular decision? Next, you need to consider the role you play in giving choices. Taking too much control of your grandchildren's decisions may lead to over-dependence and difficulty making independent decisions as they mature. On the other hand, being permissive can lead to too much independence and can result in the failure to recognize negative consequences for actions. So, how do you find the balance? Begin by asking yourself the following questions:

\section{If I realize my behavior is too controlling...}

- $\quad$ Can I trust my grandchild to do what he is ready to do?

- Am I willing to let her make safe decisions and learn from her mistakes?

- Can I let go for the sake of creating a healthy relationship?
If I realize my behavior is too permissive...

- Am I aware of the importance in guiding my grandchild's choices?

- Am I willing to provide support in helping him make decisions?

- Am I willing to play an active role in her life for the sake of creating a strong relationship?

\section{Ability to Adapt}

Learning to adapt to change takes practice. It is not easy when you have a set way of believing or doing things. Adapting means making compromises and perhaps changing the way you react to situations. Make sure you chose your battles wisely and consider what's most important in your grandchild's development.

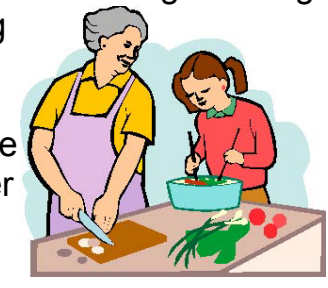

For example, suppose you always have dinner ready at 5 p.m. Your grandchild has recently decided she wants to join the school band and will not get home till 6 p.m. Do you. a) change dinner time on band nights, or b) tell her she can't join the school band? What if your 15-year-old grandson decides to grow his hair long and you dislike how it looks. Do you a) tell him while living with you, he is not allowed to have long hair, or b) permit him to have long hair because you realize this is a harmless way of expressing himself.

If you answer a) change dinner time on school nights, and b) permit him to have long hair, you have shown adaptability. By being adaptable, you're well on your way to building strong relationships.

Remember, change is inevitable. By adjusting to new situations you can prevent unnecessary conflict.

\section{Good Communication}

Good family communication opens the doors to healthy relationships. However, genuine communication is not always easy. It takes heartfelt commitment and effort by everyone in the family. Below are a few characteristics of good family communication:

\section{Be a Good Listener}

Being a good listener means giving a person your undivided attention without interruptions. It means stopping and thinking before judging or reacting. Jumping to conclusions can occur when we fail to listen to what another person is saying-we hear what we want to hear instead of what is actually said. To avoid this barrier, you need to make a 


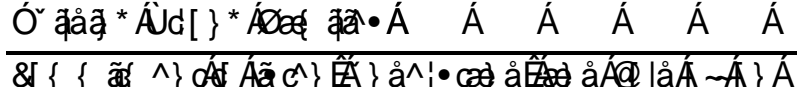
P DNQJIDITXIFNIXGJP HQW

[

Use Kind Words!

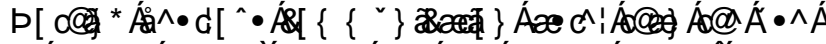
RIXQNQGZRLGV: KHQI RXIXVHXQNQGZRLGMD SHRSOIMAQGQRUMTIOMAQMUI RXII7 KH IFQRMHXSIDQG

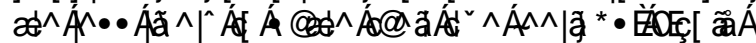

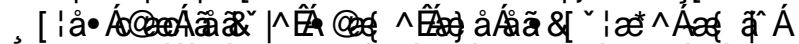

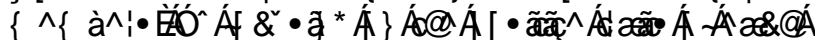
IDP LQPP HP EHUI RXIKHQSIFHDAADIFIP DUARIIP XWLO

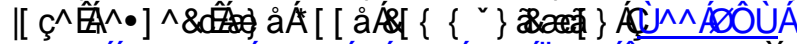

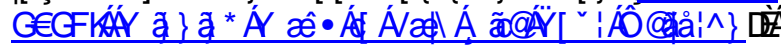

Take the Other's Perspective

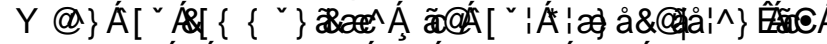
IP SRLWDQMRU HFRJQ4 HDQGH SUMMI RXU

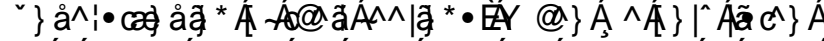

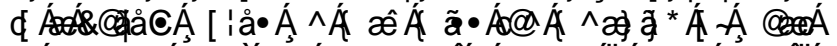

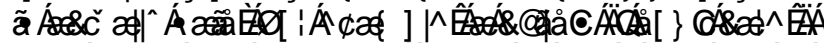

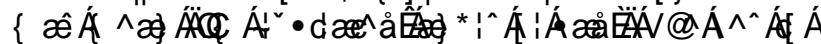

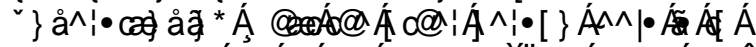
DFNQRZ OIGJHIKLVRUKHOIHOQJVI<RXIP IJKUKDI II

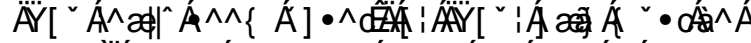
DZIXOL: KHQMRP HRQHIMNHMMXIMP HIXXQQHWWDQG

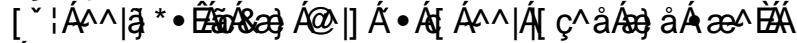
[?

' HMHRSLQJIMXHINQRZ OGJHIDQGMNQIUTXIUHGNR] KDYHMURQJ IUHODURQMISVMDNHMSUDFWHIDQG

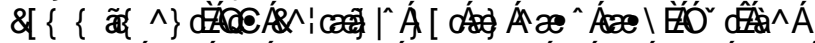

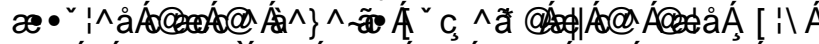

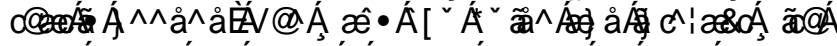
IRXUIDP LOIZ LOP DNHDIOMRIIIP SDFWRQI RXU JUDAKLQHQTा [

\section{Develop Your Skills with Practice} ]

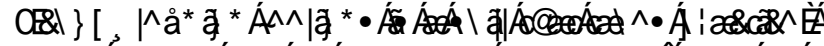
0 DQ $\triangle S H R S$ PIUHORQNDGWRQDOHNSRQMHMVXFKDV]

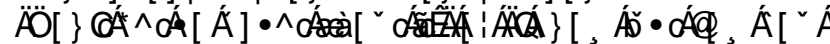

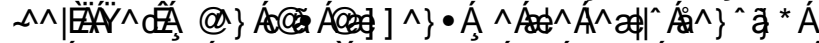

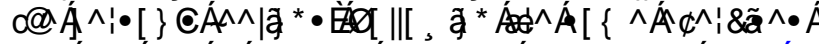

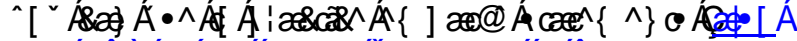

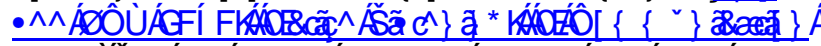
7RROI/ IWMAHFKLGMSRMEOAIIHOQJUDQGI RXU

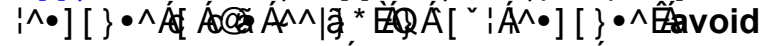
asking questions RUgiving advice.

\section{([DP SOM}

Child:[1- HQQUHUP DGHIXQRIIP HIQQMFKRROI]

[

Child's feeling: $\square$ ( P EDUDMP HQW

Wrong response: : KDWRG RXIGRMRIKHU

Correct response:[7 KDWP XWKDYHEHHQ

HP EDUDMQJW
[ 7 SDJH Practice Your Skills Below

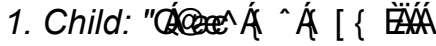

Child's feeling:

Wrong response:

Correct response:

(]

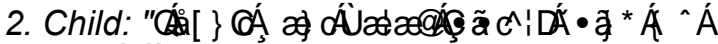
FQPXRHMDI]

Child's feeling:

Wrong response:

Correct response: (]

3RWEOL\$QVZHEMII

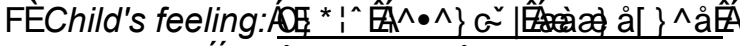

(1) GMDSSRQAHG

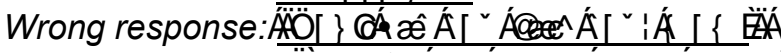

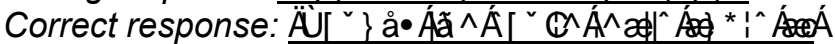

[1] $\underline{0 \mathrm{RP}}$

(1)

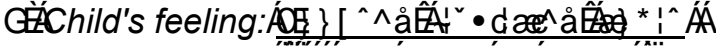

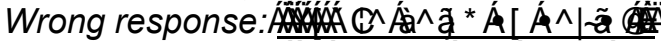

Correct response:II, LDQQRI VI RXIZKHQMKHERURZV

(1) IRXUFARMYMD

[

References

0

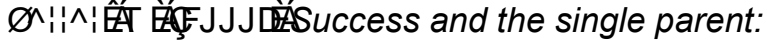
Positive parenting - The communication puzzle!

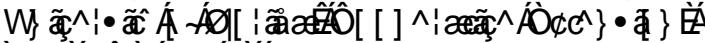

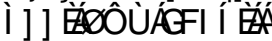

[

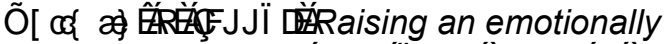

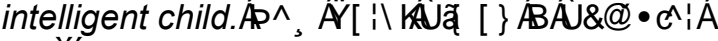
,QFW

(]

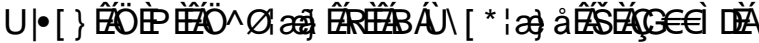
Marriages and Families: Intimacy, diversity, and

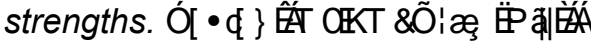

1

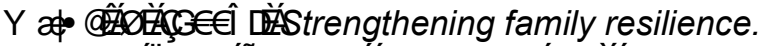
1 HZL<RWI* XIORLG3 XEIFDURQ, QFाप] 